\title{
Clinicopathological evaluation and outcome of mycosis fungoides
}

\author{
Ilkin Zindanci ${ }^{1}$, Mukaddes Kavala ${ }^{1}$, Ebru Zemheri ${ }^{2}$, Emek Kocaturk ${ }^{1}$, Burce Can ${ }^{1}$, \\ Zafer Turkoglu ${ }^{1}$, Melek Koc ${ }^{1}$, Seyma Ozkanli ${ }^{2,}$, Filiz Topaloglu ${ }^{3}$ \\ ${ }^{1}$ Department of Dermatology, Istanbul Medeniyet University, Goztepe Training and Research Hospital, Istanbul - Turkey \\ ${ }^{2}$ Department of Pathology, Istanbul Medeniyet University, Goztepe Training and Research Hospital, Istanbul - Turkey \\ ${ }^{3}$ Department of Dermatology, Bartin State Hospital, Bartin - Turkey
}

\section{Email address:}

ilkin.dr@gmail.com (I. Zindanci),mkavala2004@yahoo.com (M. Kavala), ebruzemheri@gmail.com (E. Zemheri), emekozgur@yahoo.com (E. Kocaturk),drburcecan@yahoo.com (B. Can), cemzalu@gmail.com (Z. Turkoglu), melektwin@hotmail.com (M. Koc), seymaozkanli@gmail.com (S. Ozkanli), filizsvet@yahoo.com (F. Topaloglu)

\section{To cite this article:}

Ilkin Zindanci, Mukaddes Kavala, Ebru Zemheri, Emek Kocaturk, Burce Can, Zafer Turkoglu, Melek Koc, Seyma Ozkanli, Filiz Topaloglu. Clinicopathological Evaluation and Outcome of Mycosis Fungoides. Science Journal of Clinical Medicine. Vol. 3, No. 4, 2014, pp. 65-69. doi: 10.11648/j.sjcm.20140304.12

\begin{abstract}
Although mycosis fungoides is the most common cutaneous T-cell lymphoma, its etiopathogenesis has not been clarified definitively and there is no standard and curative treatment method. Medical records of 57 patients diagnosed with mycosis fungoides by clinical and histopathological findings were retrospectively reviewed in our clinic. Complete blood count, erythrocyte sedimentation rate, peripheral blood smear, biochemical findings, chest radiographs, and computerized tomography of all patients were reviewed; patients were staged using TNM system. The clinical presentation was classical patch/plaque form in 44patients and other forms in 13. According to TNM staging, 9patients were stage 1a, 38 were stage $1 \mathrm{~b}$, 5 were 2a, and 2 were stage 3 , and 2 were stage $4 \mathrm{a}$. The pathological findings were basal alignment of lymphocytes, reticular fibroplasia, atypical lymphocytes, and epidermotropism. Remission was achieved by topical imiquimod in 2patients, phototherapy in 30, and phototherapy and systemic treatment in 8 . Remission rate with narrow band UV B was $72 \%$, and that of psoralen UV A was $85.71 \%$. Ten patients in remission had recurrence. Age, sex, duration of disease, and clinical presentation had no effect on remission or recurrence of mycosis fungoides. Reticular fibroplasia is a supporting histopathological finding in mycosis fungoides, together with basal alignment of lymphocytes, atypical lymphocytes and epidermotropism. Topical imiquimod treatment for local lesions and phototherapy for widespread lesions are effective, and psoralen UVA treatment seems to be more efficient than narrow band UVB.
\end{abstract}

Keywords: Mycosis Fungoides, Histopathology, Epidemiology, Remission, Recurrence

\section{Introduction}

Mycosis fungoides (MF) is the most common cutaneous T-cell lymphoma, and is characterized by malignant proliferation of $\mathrm{CD} 4 \quad(+) \mathrm{T}$ lymphocytes. The etiopathogenesis has not been clarified definitively, with viral, environmental and genetic factors all being suspected. ${ }^{[1]}$ The definitive diagnosis is made by histopathological examination. There is no standard and curative treatment method; therefore, treatment options differ by disease stage, age, and tolerance of the patient.

The purpose of this study was to overview the demographic and clinicopathological characteristics of the
MF patients followed in our clinic and to compare their responses to different treatment modalities.

\section{Materials and Methods}

\subsection{Study Design and Population}

Our study group was composed of 57 patients who were diagnosed with MF by clinical and histopathological findings between 2005 and 2011. Patient records were overviewed retrospectively, and patient age and sex, and duration of disease were recorded. Complete blood count, erythrocyte sedimentation rate, peripheral blood smear, biochemical findings, chest radiographs, and computerized 
tomography of all patients were reviewed, and patients were staged using the TNM system. ${ }^{[2]}$ Stages $1 \mathrm{a}, 1 \mathrm{~b}$ or $2 \mathrm{a}$ were accepted as early stages, while stages $2 b, 3$ or 4 were regarded as advanced. ${ }^{[2]}$ All lymph node biopsies, bone marrow aspirations, and organ biopsies of patients suspected of having systemic involvement were re-evaluated by the same pathologist, and histopathological findings were recorded. Control biopsies were taken after the $30^{\text {th }}$ and $60^{\text {th }}$ treatment sessions to verify clinical progress histopathologically, and patients in whom neoplastic infiltration was not seen were accepted as being in remission.

Patients were grouped by age intervals $(0-30,30-60$ or $60-90$ years), duration of disease $(<1,1-5$ or $>5$ years $)$, tumor stage (early or advanced), and treatment method (topical treatment, phototherapy alone, phototherapy with systemic treatment).

\subsection{Evaluation Criteria}

The demographic, clinical and histopathological characteristics of patients were evaluated. The effects of stage, duration, clinical variant of the disease, and treatment on the rates of remission and recurrence were also evaluated.

\subsection{Statistical Analysis}

The data were analyzed using the NCSS 2007 and PASS 2008 statistical software programs. In addition to descriptive statistics (mean, standard deviation and frequency), cross-tab statistics were utilized for comparison of data.

\section{Results}

\subsection{Patient Demographics}

Of the 57 patients, $29(50.9 \%)$ were female and $28(49.1 \%)$ were male (female: male ratio, 1.03. The mean age of the patients was 47.22 \pm 16.42 years (range: 4-86 years); $43.89 \pm 45$ years for female, and $50 \pm 67$ years for male, patients (Figure 1).

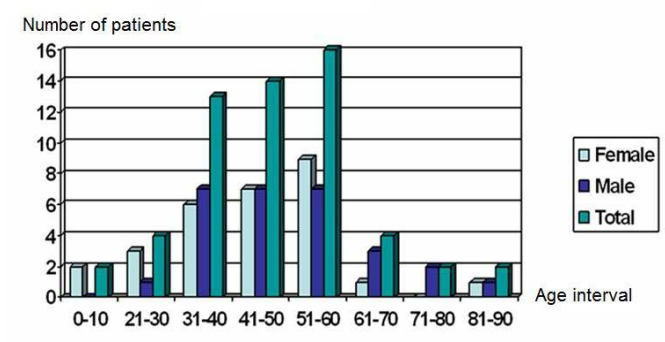

Figure 1. Distribution of MF patients to the age groups.

\subsection{Clinical Characteristics}

The time interval between the first sign of the disease and diagnosis was 1-24 months, with a mean of $58.1 \pm 52.82$ months (female patients: $55 \pm 53.48$ months; male patients: $62 \pm 52$ months). Except for one patient whose father had MF, there was no family history of lymphoproliferative diseases.
The clinical presentation of the disease was classical patch/plaque form in 44 patients $(77.2 \%)$ and other clinical forms in 13 patients $(22.8 \%)$ : hypopigmented in 2, poikilodermic in 5 , erythrodermic in 3 , follicutropic in 2 , and pityriasis-lichenoides-chronica-like in 1. There was no difference between the age and sex groups in terms of the clinical presentation of the disease ( $\mathrm{p}>0.05$, data not shown).

According to the TNM staging system; 9 patients were stage $1 \mathrm{a}(15.78 \%), 38$ were $1 \mathrm{~b}(66.66 \%), 5$ were $2 \mathrm{a}(8.77 \%)$, 2 were stage $3(3.5 \%)$. and 2 were stage $4 \mathrm{a}(3.5 \%)$.

\subsection{Laboratory and Histopathological Findings}

Sedimentation rate, peripheral blood smear, and biochemical profile of all patients were within normal limits. Only one patient had atypical lymphoid cells $(5 \%)$ in the peripheral blood smear. Both lymph node and bone marrow biopsies of this patient were within normal limits.

Lymph node biopsies were performed on 10 patients, 7 of whom were diagnosed with dermatopathic lymph nodes; the remaining 3 biopsies showed neoplastic infiltration. Bone marrow biopsies of these 10 patients were negative for neoplastic infiltration. T-cell-gene rearrangement investigation could be performed only in the patient who was diagnosed with pityriasis-lichenoides-chronica-like MF.

The histopathological re-evaluation of the diagnostic biopsies revealed four common findings: basal alignment of lymphocytes $(87.1 \%)$, reticular fibroplasia (85.9\%), atypical lymphocytes (68.42\%), and epidermotropism (63.1\%). Rates of basal alignment of lymphocytes, reticular fibroplasia, atypical lymphocytes $(\mathrm{p}<0.001$ for each), and epidermotropism $(\mathrm{p}<0.05)$ were significantly higher in $\mathrm{MF}$ patients. Interphase dermatitis, Pautrier abscess, spongiosis, follicular mucinosis, and large cells were observed rarely $(\mathrm{p}<0.01)$ (Table 1).

Table 1. Histopathologic changes in diagnostic biopsies of MF patients

\begin{tabular}{llll}
\hline Histopathologic changes & $\mathbf{n}$ & \% & p value* \\
\hline Basal alignment of lymphocytes & 50 & 87.71 & 0.001 \\
Reticular fibroplasia & 49 & 85.96 & 0.001 \\
Atypical lymphocytes & 39 & 68.42 & 0.005 \\
Epidermotrophism & 36 & 63.15 & 0.047 \\
Psoriasiform hyperplasia & 31 & 54.38 & 0.508 \\
Interphase changes & 15 & 26.31 & 0.001 \\
Pautrier mikroabcess & 15 & 26.31 & 0.001 \\
Spongiosis & 9 & 15.78 & 0.001 \\
Poikilodermatoid changes & 5 & 8.77 & 0.001 \\
Large cell transformation & 3 & 5.27 & 0.001 \\
Folikuler musinosis & 2 & 3.50 & 0.001 \\
Granuloma structure & 0 & 0 & $\mathbf{0 -}$ \\
\hline
\end{tabular}

*Chi-square test for single variance.

Among the patients in whom immunohistochemical evaluations were performed, one was diagnosed with CD8 (+) MF and another showed anaplastic transformation. Both patients' peripheral blood smears were normal, and because there were no palpable lymph nodes, lymph node biopsies were not performed. 


\subsection{Treatment Outcome}

Following treatment, remission was seen in 40 of 57 patients $(70.2 \%)$. Ten patients $(25 \%)$ who entered remission had recurrence. The time interval between remission and recurrence was 4-36 months with a mean of $16.06 \pm 8.44$ months. Although statistically insignificant, longer disease duration was associated with lower remission and higher recurrence rates (Table 2). Age, sex and clinical presentation had no effect on remission or recurrence rates $(\mathrm{p}>0.05$ for all, data not shown). Progression of disease, which was described as progress to a subsequent stage, was not seen during the 5-year follow-up.

Table 2. Effect of duration of disease on remission and recurrence rates

\begin{tabular}{llllll}
\hline \multicolumn{5}{c}{ Duration of disease } & \\
\cline { 2 - 5 } & $<\mathbf{1}$ year & $\mathbf{1 - 5}$ years & >5 years & p value* \\
\hline $\begin{array}{l}\text { Remission } \\
(\%)\end{array}$ & rate, $\mathrm{n}$ & $8(100.0)$ & $19(79.2)$ & $13(65.0)$ & 0.131 \\
Recurrence, $\mathrm{n}(\%)$ & $1(12.5)$ & $4(21.1)$ & $5(38.5)$ & 0.353 \\
\hline
\end{tabular}

*Chi-square test.

\subsection{Treatment Modalities}

Table 3. Number of patients in terms of disease stage, model of treatment, remission, and recurrence

\begin{tabular}{lllll}
\hline Stage & Treatment & Remission & Recurrence & $\begin{array}{l}\text { Ongoing } \\
\text { treatment }\end{array}$ \\
\hline \multirow{3}{*}{ 1a } & nbUVB & 3 & 0 & 0 \\
& PUVA & 1 & 0 & 0 \\
& Re-nbUVB & 1 & 0 & 1 \\
& Imiquimod & 2 & 0 & 0 \\
& nbUVB & 14 & 7 & 2 \\
1b & PUVA & 10 & 3 & 2 \\
& Re-nbUVB & 3 & 0 & 0 \\
& Re-PUVA & 1 & 0 & 1 \\
& Re-nbUVB+IF & 2 & 0 & 0 \\
\multirow{2}{*}{ 2a } & nbUVB & 1 & 0 & 0 \\
& Re-nbUVB & 1 & 0 & 0 \\
& PUVA & 1 & 0 & 0 \\
3 & Re-PUVA & 0 & 0 & 1 \\
$4 a$ & Re-PUVA+IF & 0 & 0 & 1 \\
& Re-nbUVB+IF & 0 & 0 & 1 \\
\hline
\end{tabular}

nbUVB: Narrowband ultraviolet B, PUVA: Psoralen ultra-violet A, Re: Retinoid (asitretin), IF: Interferon.

Ten of the 57 patients were still on treatment and 5 discontinued therapy (Table 3 ). Two patients died during the treatment period. One of them was a stage $2 \mathrm{a}$ patient, who had a cause of death other than MF, and the other was a stage 4a patient who died of treatment complications. All of the patients who had remission $(n=40)$ were in early-stages; however, none of the late-stage patients had remission. Remission was achieved by topical imiquimod in 2 patients $(5 \%)$, phototherapy in $30(75 \%)$, and phototherapy and systemic treatment in $8(20 \%)$.

Both patients who entered remission as a result of topical imiquimod treatment had only a single plaque lesion in the inguinal region, and recurrence was not seen in these patients. Of the 38 early-stage patients, remission was achieved in $30(79 \%)$ with phototherapy alone, and in 8 $(21 \%)$ with the combination of phototherapy and systemic treatment. The remission rate with narrowband UV $B$ (nbUVB) was $72 \%(18 / 25)$, and that with psoralen UVA (PUVA) was $85.71 \%(12 / 14)$. The recurrence rate after nbUVB treatment was $38.8 \%(7 / 18)$, and that after PUVA was $25 \%(3 / 12)$.

\section{Discussion}

MF has an annual incidence of 0.29 to $0.50 / 100000 .^{[3,4]}$ The incidence of MF is reported to be high in black and low in Asian and Chinese people. ${ }^{[3]} \mathrm{MF}$ is two-fold more common in men than women. ${ }^{[1]}$ Takaoki et al. reported a male: female ratio of $4: 1{ }^{[6]}$ In our patient group the male: female ratio was $<1$. The mean age at the time of diagnosis has been reported as $56-64$ years, with $75 \%$ of patients $>50$ years of age in a number of studies. ${ }^{[5-8]}$ Our patients' mean age was 47.22 years, and $42 \%$ were $>50$ years of age; both of which were lower in comparison to the other series. Anadolu et al. reported the mean age at the time of diagnoses as 45.6 years. ${ }^{[9]}$ In a study from Singapore, $25 \%$ of $131 \mathrm{MF}$ patients were children, and the mean age was 33 years. ${ }^{[10]}$ Our findings are compatible with the study of Anadolu et al. ${ }^{[9]}$ Although MF is known as a disease of adulthood, it is also seen in younger age groups. In our study, patients aged $<20$ years comprised $3.5 \%$ of the total, and this finding is compatible with previous studies that reported a rate of 0.5 $5 \%$. $^{[8,11]}$

The time interval between recognition of the first skin lesion and diagnosis has been reported to be $2-10$ years. ${ }^{[12]}$ In our study, the mean time interval was $58.1 \pm 52.82$ months. This time interval tends to be prolonged because of the low numbers of complaints by patients, the fact that MF mimics other skin diseases and multiple biopsies are required for definitive diagnosis.

Although the precise etiopathogenesis of the disease has not been established, some anecdotal familial MF cases support a role for genetic factors. ${ }^{[13]}$ One of our patient's fathers was also diagnosed with MF, which supports the existence of a genetic component.

Although the majority of our patients were in the patch/plaque stage, other variants were also seen. Hypo pigmented MF, which is usually reported in children, was diagnosed in two of our adult patients. ${ }^{[1]}$ Our patients were mostly in stage $1 b$, suggesting that they sought medical help when the skin lesions became extensive, without any accompanying symptoms.

Definitive diagnosis of MF is made by histopathological examination. Especially in the early stages, diagnostic histopathological findings are not always detected, making recognition of MF difficult. In our study, two of the most common histopathological findings were atypical lymphocytes and epidermotropism, which is compatible with the report of $\mathrm{Ku}$ et al. ${ }^{[7]}$ However, Pautrier micro abscess and interphase changes were less common, and 
basal alignment of lymphocytes and reticular fibroplasia were significantly more common than in the study of $\mathrm{Ku}$ et al. Guitart et al. determined three major (intensive lymphocytic infiltration, epidermotropism, and atypical lymphocytes) and two minor (reticular fibroplasia of papillary dermis, and lymphocytic infiltration without inflammatory findings) criteria in an attempt to standardize the histopathological findings of $\mathrm{MF}^{[14]}$ Reticular fibroplasia, one of the minor criteria, is characterized by dense collagen bundles surrounding lymphocytes in the reticular dermis. Reticular fibroplasia, which was observed by $\mathrm{Ku}$ et al. at a rate of $16.1 \%$, was detected in $85.9 \%$ of our skin biopsies. ${ }^{[7]}$ Our histopathological findings demonstrate that, together with the basal alignment of lymphocytes, atypical lymphocytes and epidermotropism, reticular fibroplasia is also an important finding that supports a diagnosis of MF.

There are no specific laboratory findings for MF, but some studies have claimed that eosinophilia can be seen, and high lactate dehydrogenase levels can be a bad prognostic indicator. ${ }^{[15,16]}$ However, in our study, there were no abnormal laboratory findings.

There is no standard treatment for MF. The clinical response to topical steroids, which are the most common treatment option for early-stage disease, is limited. In this study, we demonstrated that topical imiquimod is a good choice, especially for localized lesions. For widespread early disease, phototherapy was effective in 78.9\% (30/38) of patients. If remission cannot be achieved by phototherapy, retinoic acid and interferon may be added to the treatment. In our study, treatment with PUVA resulted in a remission rate of $85.7 \%$ and a relapse rate of $25 \%$. For nbUVB, these rates were 75.2 and $38.8 \%$, respectively. Remission rates of $71,78.3$ and $80.4 \%$ for PUVA, and 68.4 and $81 \%$ for nbUVB have been reported. ${ }^{[7,9,17,18]}$ Our results are compatible with these. We found that PUVA treatment was more effective, and relapse rates were lower, than for nbUVB. In patients who were intolerant to PUVA, nbUVB was also found to be effective. The progression rate of MF has been reported to be $15 \%{ }^{[7]}$ In our study, no disease progression was observed. This is because most of our patients were in the early stages of the disease and the follow-up interval was short.

The main limitation of our study was that we were unable to perform immunohistochemical analyses, because at the time of the study, our hospital had no such facilities. However, our findings are still valuable epidemiologically at the local level for the population around Istanbul.

In conclusion, reticular fibroplasia is also a supporting histopathological finding in MF, together with basal alignment of lymphocytes, atypical lymphocytes and epidermotropism. Especially in the early stages of the disease, topical imiquimod treatment for local lesions and phototherapy for widespread lesions are effective, and PUVA treatment seems to be more efficient than nbUVB. Further studies with a larger number of patients and a longer follow-up should be conducted to compare the options for MF treatment.

\section{References}

[1] Willemze R: Cutaneous T-cell lymphoma. Dermatology. In: Bolognia J, Jorizzo J, eds. 2nd ed. Spain: Mosby, 2008: 1867-1886.

[2] Olsen E, Vonderheid E, Pimpinelli N, Willemze R, Kim Y, Knobler R. Revisions to the staging and classification of mycosis fungoides and Sezary syndrome: a proposal of the International Society for Cutaneous Lymphomas (ISCL) and the cutaneous lymphoma task force of the European Organization of Research and Treatment of Cancer (EORTC). Blood 2007; 110: 1713-1722.

[3] Koh HK, Charif M, Weinstock MA. Epidemiology and clinical manifestations of cutaneous T-cell lymphoma. Hematol Oncol Clin North Am 1995; 9: 943-960.

[4] Siegel RS, Pandolfino T, Guitart J, Rosen S, Kuzel TM. Primary cutaneous T-cell lymphoma: review and current concepts. J Clin Oncol 2000; 18: 2908-2925.

[5] Takaoki I, Yuko T, Michihito N. Cutaneous lymphoma in Tokyo: analysis of 62 cases in dermatology clinic. Int $\mathrm{J}$ Dermatol 2001; 40: 37-40.

[6] vanDoorn R, Van Haselen CW, van Voorst Vader PC, Geerts ML, Heule F, de Rie M, Steijlen PM, Dekker SK, van Vloten WA, Willemze R. Mycosis fungoides: disease evolution and prognosis of 309 Dutch patients. Arch Dermatol 2000; 136: 504-510.

[7] $\mathrm{Ku} \mathrm{LS}$, Lo KK. Mycosis fungoides--a retrospective study of 40 cases in Hong Kong. Int J Dermatol 2005; 44: 215-220.

[8] Zackheim HS, McCalmont TH, Deanovic FW, Odom RB. Mycosis fungoides with onset before 20 years of age. J Am Acad Dermatol 1997; 36: 557-562

[9] Anadolu RY, Birol A, Sanli H, Erdem C, Tursen U. Mycosis fungoides and Sezary syndrome: therapeutic approach and outcome in 113 patients. Int J Dermatol 2005; 44: 559-565.

[10] Tan ES, Tang MB, Tan SH. Retrospective 5-year review of 131 patients with mycosis fungoides and Sézary syndrome seen at the National Skin Centre, Singapore. Australas J Dermatol 2006; 47: 248-252.

[11] Quaglino P, Zaccagna A, Verrone A, Dardano F, Bernengo MG. Mycosis fungoides in patients under 20 years of age: report of 7 cases, review of the literature and study of the clinical course. Dermatology 1999; 199: 8-14.

[12] Jörg B, Kerl H, Thiers BH, Bröcker EB, Burg G. Therapeutic approaches in cutaneous lymphoma. Dermatol Clin 1994; 12 : 433-441.

[13] Baykal C, Büyükbabani N, Kaymaz R. Familial mycosis fungoides. Br J Dermatol 2002; 146: 1108-1110.

[14] Guitart J, Kennedy J, Ronan S, Chmiel JS, Hsiegh YC, Variakojis D. Histologic criteria for the diagnosis of mycosis fungoides: proposal for a grading system to standardize pathology reporting. J Cutan Pathol 2001; 28: 174-183.

[15] Kural YB, Su O, Onsun N, Uras AR: Atopy, IgE and eosinophilic cationic protein concentration, specific IgE positivity, eosinophil count in cutaneous $\mathrm{T}$ Cell lymphoma. Int J Dermatol. 2010 Apr;49(4):390-5. 
[16] Vidulich KA, Talpur R, Bassett RL, Duvic M. Overall survival in erythrodermic cutaneous T-cell lymphoma: an analysis of prognostic factors in a cohort of patients with erythrodermic cutaneous T-cell lymphoma. Int J Dermatol 2009; 48: 243-252.

[17] Diederen PV, van Weelden H, Sanders CJ, Toonstra J, van
Vloten WA. Narrowband UVB and psoralen-UVA in the treatment of early-stage mycosis fungoides: a retrospective study. J Am Acad Dermatol 2003; 48: 215-219.

[18] Ponte P, Serrão V, Apetato M. Efficacy of narrowband UVB vs. PUVA in patients with early-stage mycosis fungoides. J Eur Acad Dermatol Venereol 2010; 24: 716-721. 